\title{
Renewable Energy: The Key to Achieving Sustainable Development of Rural Bangladesh
}

\author{
M. S. Islam, A. M. H. R. Khan, S. Nasreen, F. Rabbi \& M. R. Islam \\ Grameen Shakti \\ Grameen Bank Bhaban (19th floor), Mirpur 2, Dhaka 1216, Bangladesh
}

\begin{abstract}
Renewable energy technologies (RETS) can help reduce poverty, energy shortage and environmental degradation such as desertification, biodiversity depletion and climate change effects in Bangladesh. The country is short of gas and electricity supply. Over-exploitation of biomass in meeting energy needs of the rural people has caused environmental degradation. RET can help solve those problems if it is widely used in the rural Bangladesh where people primarily depend on biomass energy. Bangladesh has enough renewable to mitigate such energy crisis and its adverse consequences. Bangladesh being an underdeveloped country, global initiative would be helpful in transferring RETs for the village households. This paper describes the glimpses of RETs in Bangladesh in terms of its policy issues, implementation, dissemination, marketing, and research and development activities. Modern RETs are still in the research, development and demonstration phase in the country. Like most of the developing countries, there is a niche market for new RETs and several private sector entrepreneurs and NGOs have tried to explore this market.
\end{abstract}

\section{Keywords}

renewable energy technology; solar home system; rural development; environmental; electricity; biogas; improved cooking stove; clean energy; energy efficiency.

\section{Introduction}

Bangladesh has major problems with energy crisis, persisting poverty and environmental degradation. With only $49 \%$ of Bangladeshis having access to electricity, the per capita energy use is only $180 \mathrm{kWh}$. Moreover, the people who are connected with the national grid are experiencing frequent load shedding. At present, the country can generate about $4500 \mathrm{MW}$ electricity, while peak demand is about 6000 MW (USAID, 2011). Therefore, the supply is unreliable. Most of the supply is limited to urban areas; access to electricity in rural areas is less than $10 \%$. RET can solve this problem by harnessing energy from country's free flowing renewable such as sunshine, wind, tidal waves, waterfalls or river current, sea waves or biomass. Use of renewable energy, increased energy efficiency and enhancement of energy security constitute a sustainable energy strategy approach.

Renewable forms of energy emit far smaller amounts of greenhouse gases compared with fossil fuels and increased energy conservation facilitates the reduction of primary fossil fuel use, thus mitigating climate change impacts while contributing to the provision of energy services and enhancing security of energy supply. Usable biomass including cow dung, human excreta, poultry litter, kitchen organic waste, aquatic plants and weeds of a village in Bangladesh can produce the amount of biogas that villagers require for cooking. The fermented slurry from biogas digester is enriched with nitrogen, potassium and other nutrients. It is, therefore, best for soil, environmental health and agricultural productivity management.

On the other hand, Bangladesh has one of the highest solar insulation on the earth. The average solar radiation varies here from $5.05 \mathrm{kWh} / \mathrm{m}^{2}$ day in winter to 8.03
$\mathrm{kWh} / \mathrm{m}^{2}$ day in summer. As Bangladesh is a compact flat country with a little geographic variation, the solar radiation data collected from one point may be treated as that of the whole country. In other word, affordable availability of RETs to the rural area could be the panacea of poverty reduction and environmental fix in Bangladesh

\section{Synergy}

The relationship between energy and economic development is crucial; the process of economic growth requires the substation of energy mix in the performance of agriculture, industrial and domestic tasks. The lack of adequate energy in rural Bangladesh has economic costs not just at the individual and household level but at the national level as well. Development in Bangladesh without corresponding increase in per capita electricity and gas consumption is, therefore, not feasible. Everyone needs energy in one form or another, for day-to-day life, for cooking, lighting, heating and so on. Consequently, energy is to be considered as a basic need along with food, water, shelter and others.

In social aspects, energy plays a key role in achieving social justice including gender justice. Low level of energy service is a serious obstacle to raising social, health and nutritional status of community. Dependence on human energy and primitive technologies for survival introduces a whole range of obstacles to social and gender equality. The rural people in general, and rural females in particular, are tapped in an unceasing cycle of works that condemns them to poor health, little or no education and deprives them in equal participation in local development programs (i.e. education, income generating activities, etc.), self governing bodies and political movements. Improved energy services can be at

* Corresponding Author's Email: g_shakti@grameen.com 
the centre of any strategy to mitigate the gender disparity.

The availability of adequate, reliable and reasonably priced source of energy is, therefore, prerequisite for the development of rural Bangladesh. Suggestions can now be made to the extent that the usage of RETs would launch a new era of appropriate technology, sustainable socio-economic and environmental development in the country.

\section{Rural Energy Needs}

More than $70 \%$ of total populations of the country live in rural areas. At present major portion of total energy needs for cooking is met by locally available biomass fuels. The rural electrification program meets a small portion of total energy needs. For overall national development there is a need to pay special attention so that the energy needs of rural areas for subsistence and productive requirements (e.g. agriculture, industries, and transport) are met on a sustainable basis. Different types of renewable energy technologies such as Solar Home System (SHS), Biogas, and Improved Cooking Stoves (ICS) are suitable for Bangladesh.

\section{A Solar Bangladesh}

SHS has been a successful story in Bangladesh. Our rural people have accepted SHS on a mass scale. Once it was thought that solar energy was not affordable for the rural people. This myth has been broken. Along with thirty partner organizations in the country, as of August 2011, over one million SHS have been installed in Bangladesh, benefiting over 6 million rural people (IDCOL, 2011). On average, more than 35,000 systems are installed every month and within the next 1 to 3 years, this rate is likely to be triple. A powerful economic model has been created to make solar energy a part of rural life, integrating one of most sophisticated technologies with the aspirations, toils and successes of the rural people. A rural family can have bright light, watch TV and power their mobile phones at the same cost as kerosene, while escaping from dim light, foul smelling smoke including health and fire hazards. Rural businesses can increase their productivity and income through extended working hours and attracting more customers.

This sector has been creating green jobs and linkage businesses especially in the rural areas. Hundreds of local youths are working in the rural areas as solar technicians. Rural women are assembling solar accessories in village based Technology Centres. Solar engineers are increasingly employed in designing SHS, working in battery factories, and other accessory related businesses. Bangladesh is on the verge of a Solar Revolution. Increased aspirations, failure of grid electricity, growing machination and disposable income have created huge potential for solar energy in rural areas.

\section{Biogas Technology}

Biogas is a proven and widely used source of energy in the country. There is now yet another wave of renewed interest in biogas due to the increasing concerns of climate change, indoor air pollution and increasing oil prices. Such concerns, particularly for climate change, open opportunities for the use of the CDM benefits in the promotion of biogas.

In spite of being insignificant in volume, the availability of biogas to very large number of rural people and to very remote areas makes the technology very suitable and effective. True, commercially produced pipeline natural gas plays and will continue to play vital role in the industrialization and urbanization of the country, but this gas will not reach the remote village households any time soon, if at all! In that respect there is no alternative to biogas for the millions of villagers. The above situation leaves the rural population to rely on the traditional biomass sources for household supply of energy. Over the last few decades there have been renewed interests and initiatives by many organizations to innovate new and improved biomass energy technologies whereby the biomass energy sources can be used more efficiently and cost effectively for the rural people. The most popular and widely used of these technologies has been the biogas technology in which biomass (cow dung, poultry dropping, agricultural residue etc) is converted into biogas. The biogas is supplied to households for use in cooking in a similar way natural gas is used. In addition, biogas may be used to light houses. Biogas can also be used to run small generator to produce electricity for running electrical household appliances like TV, electric light, fridge etc.

Biogas technology is the most ideal technology for rural Bangladesh. Biogas plant is built with simple technology and uses raw material easily available with the rural households -- mostly cow dung. Biogas is a kind of gas generated when biomass i.e. cow dung or other animal dung or biodegradable organic masses are stored in underground chamber in an anaerobic condition (absence of oxygen). It is a kind of anaerobic bacteria that produces the biogas from the organic debris. The composition of biogas is mainly methane (60 to $70 \%$ ) with lesser amount of carbon dioxide (30 to $40 \%$ ) and traces of hydrogen and nitrogen. It is a colourless gas and burns in similar way as natural gas (it actually burns at $800{ }^{\circ} \mathrm{C}$ compared to natural gas which burns at $1000{ }^{\circ} \mathrm{C}$, both suitable for cooking and any other household application). A biogas plant consists of a brick made underground chamber about 10 feet in height connected to a smaller surface feeding chamber on one side and a debris outlet chamber on the other side. Cow dung or other biomass material with water (in 1:1 ratio) are fed once a day into the underground chamber from the surface and biogas is generated and accumulated at the top part of the chamber. The gas is tapped by inserting a rubber pipe and supplied to kitchen or other places in the house. After producing gas, the residue is moved to the outlet chamber under the gas pressure and incoming new biomass materials and is deposited in a pit as a very good quality fertilizer ready to use in the field.

In Bangladesh about 44 million tons of fuel wood is used in rural areas as cooking fuel each year (Islam and Islam, 2011). These destroy our forest and have negative impact on weather, land and environment. Also, as other biomasses like leaves, cow dung and agricultural residues are burnt as cooking fuel, these can no more help as a natural fertilizer as part of the cycle that keeps 
the balance in the ecosystem. In all the above counts, use of biogas technology will bring about benefits to the environment and the people. It certainly upgrades an ageold inefficient and poor energy use practice into a more efficient and scientific one.

\section{Improved Cooking Stove}

ICS are those traditional stoves upon which some modifications have been made to give higher thermal efficiencies. The efficiencies are defined as a fraction of heat content of the fuel fruitfully utilized. Improved stove save $50-60 \%$ traditional fuel as compared with traditional ones. Total amount of traditional fuel consumption in the country is about 39 million tons annually. If improved stoves popularized in the country and if it saves $50 \%$ traditional fuel, then annually about 19.5 million tons of traditional fuel will be saved. The reductions of traditional fuels by improved stoves, therefore, have lower emission of green house gases in the atmosphere. It also helps conserve the forest resources of the country.

In Bangladesh it will be difficult to supply natural gas for cooking purpose to the every households of the country. Therefore, improved stoves have bright future in the country. Large scale dissemination of improved stoves in the country can conserve the local forest and change the social life to a great extent.

\section{Factors of Success}

RET is the technology of the Future. But unless this technology can reach the most deprived and vulnerable group in the world today - the millions of rural people who suffer most from the energy crisis - this technology will neither reach its full potential, nor will the economic and social problems of the world be solved. In the early stage when very few POs started to promote renewable among the rural people, village electrification was considered the domain of government programs and development aid, leaving a legacy of inefficiency and squandered subsidies. Eventually some innovative financing scheme had been created to make RET affordable for rural people.

\section{Innovative Financial Schemes to make the Technology Affordable at the same cost as Kerosene}

RET is still expensive relative to traditional energy sources. One of our initial challenges was to bring down the high upfront cost of a solar system. An innovative installment based financial scheme worked fantastically which reduced the cost of a system to monthly kerosene cost. This is at the central core of our success story. It also allowed us to expand our market and reach economies of scale which further allowed us to bring down our costs per unit and engage in a profitable, sustainable business. Instead of renting, we focused on ownership which translates into better care and longevity of the system. As the price of traditional energy sources rises, renewable energy technology is becoming more and more viable, especially due to its low per unit cost. But, the high upfront cost of the technology is still a major obstacle in generating the shift away from traditional fossil fuels and must be dealt with.
Focus on Empowerment, Income Generation \& Cost Savings

Tiding the technology with income generation, cost savings, higher standard of living, and especially social and economical empowerment is very important. In rural Bangladesh, solar power became synonymous with social status, better living and more income. A rural family could save up to BDT 700 per month in energy cost while enjoying televisions and other modern amenities. Once the installments were paid off within 3 years, there was minimum running cost for nearly 20 years. This made solar a more attractive option than kerosene. They were social benefits also. The burden of women were reduced as they no longer had to clean kerosene soot, work under dim light and they could take part in home based income generating activities. Children could study under solar light and get connected to the outside world through televisions. For rural businesses, solar power meant productivity, more sales, income and jobs. A rural business could double its turnover by using solar while minimizing energy cost. Solar power especially helped improve connectivity, increase the sales of electronic goods, create new business opportunities such as mobile phones charging shops, electronics repair, maintenance shops, community television centers etc.

\section{A Strong Grassroots Network to provide after sales} service, right at the doorsteps of the rural people

Rural people are unlikely to invest in a technology which is not durable and no after sales service is available. We focused on creating a vast network of rural engineers who developed one to one rapport with their customers. They visited each client's home monthly to offer free after sales service for nearly 3 years. Long term warranty (i.e. 20 years for panels, 5 years for batteries and 3 years for charge controllers etc.) for SHS plus buyback option under which a client can return his /her system, if the area becomes grid connected is a wonderful weapon to explore renewable in the rural areas. A rural network of women technicians has been created to assemble and repair solar accessories to ensure low cost, quick effective repair, maintenance services and availability of spare parts, right at the door steps of the users. It also trained customers on how to take care of their systems and provides them with training manuals. This meant well kept systems, minimum repair and maintenance cost for both clients and us.

\section{Capitalizing on Community Forces}

One reason for this sector's success was the active involvement of the rural community. Rural people were completely unaware of renewable energy technologies. Winning rural confidence played a vital role. Engagement of community leaders and organizing demonstrations helped a lot. Special focus on creating local stake-hold - social and economical was significant. In order to keep the goodwill, the POs offered special packages for rural schools and madrasa. Introduction to scholarship for school children of solar users and design of especial programs for rural school children to seed awareness of renewable in the next generation were also done. Installation and maintenance the systems, 
understand the local market and customs were accelerated by the local youth. Setting up of village based technology centers to assemble all solar accessories, creating jobs for local women was also essential. This bottom-down, decentralized approach has helped us to keep operating costs low, and gain acceptance by the local communities. GS was unique in that sense that GS not only provided clean energy solutions, but also created powerful social and economical forces for their adoption. For example, GS created jobs for young men and women who could earn enough in few years to install a system themselves.

\section{Building institutional capacity}

Fully developing the infrastructure for renewable in Bangladesh requires more than just putting solar systems on the market. Many projects in the country also work to remove the barriers to more widespread use of renewable systems and build the skills along with the partner organizations. These POs facilitate a package of interventions to support Bangladeshi institutions in overcoming major market barriers. These institutions include rural electricity cooperatives, community-based organizations, NGOs, microfinance institutions, and private-sector groups.

\section{Women as Active agents of Change}

GS has set up village based GTC to train and empower young women to become Renewable Energy Technicians and Entrepreneurs. This was one of our most innovative and successful programs. These centers managed by women engineers train rural women in renewable energy technology, enabling hundreds of rural women to earn extra money. These women who belong to most deprived class of their communities have learnt skills on assembling, installing and repairing and maintaining one of the most up to date technologies in the world. They assemble and repair solar accessories such as charge controllers, mobile chargers, invertors etc. This has enhanced their social and economic value in their communities and contributed to women empowerment. These women have are the backbone of our local production and repair network helping rural people access cost effective, efficient services right at their door steps. They are powerful voices motivating other women, their families and neighbors to install solar and other renewable.

\section{Appropriate Product Design \& Diversification}

GS with other POs promote and design high quality, innovative products which meet the diversified needs of rural clients. The customer tailored packages ranging from 10 to 135 watts allow a rural client to save energy, generate income and become the owner of a system after 1 or 3 years, at the same cost of kerosene. The standard 50 watt system allows a rural client enjoy 4 bright lights, watch televisions and power mobile phones. For the lower income grouped, there are 10 to 20 watt systems and micro-utility model which allows sharing of one system by many. Depending on the income of a rural client, the design products varies to power computers, DC fans, refrigerators and income generating activities.

\section{A Listening Culture coupled with Strong Quality Control}

GS remain tuned to local needs by listening to our staffs and clients. The strong Audit and MIS system help GS seek new opportunities, meet challenges and forge ahead. We are flexible and localized in our approach, but without sacrificing quality. SHS registered exponential growth after the advent of IDCOL with the number of service providers, suppliers, manufactures multiplying. Bangladesh gained the capacity to manufacture all solar accessories expect for the solar panel.

\section{Challenges and Opportunities}

Our government has set a target of reaching all with electricity by 2020 . Momentum has been created for solar power which our rural people have accepted whole -heartedly. Solar \& other renewable are in a position to play a very important role to complement government efforts to take electricity to all by 2020 . We are yet to reach the penetration rate of mobile phones or televisions which has reached more than half portion of the rural market. We are yet to reach cost effectiveness to reach all rural income groups especially the lower income group in large numbers.

\section{Challenges:}

- There are more than 30 organizations engaged in the rural renewable energy sector. Expect for a few, majority have a very small client base. Cutting edge business culture is yet to develop in this field because of the prevalence of NGO culture. There has been very little incentive for innovation or new product development because most of the organizations depend on guaranteed soft loans from IDCOL.

- Present practice of vast rural network of branches and engineers translates in huge transaction cost and slow penetration rate. Lack of good communication especially during the rainy season constraints movements and increases transport cost. Seasonal variation in the income of the rural people makes collection of installment difficult. This is not cost effective or feasible in the long run.

- Training and retaining efficient human resource at the field level is also difficult. Incentive is low compared to the hard work. It is difficult for organizations to increase incentives in order to keep their costs low.

- There is lack of skilled engineers who can make cost effective and efficient SHS designs especially for productive applications.

- Another major challenge is high battery prices and inability to source quality materials or accessories cost effectively.

- Huge Tax and VAT are charged on import of all raw materials except solar panels. This increases the cost of local manufacturing of 
solar accessories which in turn increases the cost of Solar Home Systems.

- There has been very little incentives from the government to popularize RET except for long term soft loan through IDCOL. Most practitioners are over dependent on IDCOL with no diversification of funding. Mainstream financial institutions are yet to take a major interest in the RET sector.

\section{Opportunities:}

- Exponential demand has been created among rural people for solar power and renewables. This is mainly due to increased price of kerosene, diesel, and lack of grid connected power, decreased price of solar energy, and especially due to growing aspiration and economic diversification of the rural people. Dependence on land or agriculture is reducing, cattle is being replaced by power tillers, tractors etc. Nearly $60 \%$ of the rural people own a television.

- Technical progress has reduced cost, increased efficiency and diversified the application of solar energy. For example, use of LED and CFL has reduced the cost of solar power, while increasing its efficiency. Pico systems ( 1 to 5 watts) can power 2 or more lights while charging mobile phones. This has brought solar technology within the reach of lower income groups. LED based systems have resulted in dramatic decrease in costs. Factors to reduce cost include efficient loads, innovative batteries, and lower module cost.

- We can use biogas technology not only generating cooking gas, but also for generating pure methane gas which can used for running vehicles, power pumps and other electronic equipment. This will facilitate rural development. Though some large sized biogas plants in Bangladesh are generating electricity, it is only for meeting the owners' own energy needs. We can scale this up if we can purify the gas and place it in cylinders. We can use all types of wastes ranging from animal dung to crop residues for this purpose. This is successful technology which has been implemented in India, Sweden and many other countries. Our Government which is promoting independent power generation should also facilitate this type of technology. We can use biogas technology in urban areas to convert wastes into electricity, gas and organic fertilizers.

- Again Biogas technology takes part in the global struggle against the greenhouse effect by reducing the release of $\mathrm{CO}_{2}$ from burning fossil fuels in two ways. First, biogas is a direct substitute for gas or coal for cooking, heating, electricity generation and lighting. Second, the reduction in the consumption of artificial fertilizer avoids carbon dioxide emissions that would otherwise come from the fertilizer producing industries. By helping to counter deforestation and degradation caused by overusing ecosystems as sources of firewood and by melioration of soil conditions, biogas technology reduces $\mathrm{CO}_{2}$ releases from these processes and sustains the capability of forests and woodlands to act as a carbon sink.

- Improved Cooking Stoves can be one of the most cost effective devices to stop in-door airpollution and reduce deforestation. In this connection, GS has already constructed around 373,969 ICSs through local technicians. A huge positive response from women have been receiving because of $50 \%$ less fuel cost and smoke free cooking. Various POs could disseminate 10 million cooking stoves by 2015 if proper initiatives are taken.

- Diversification of rural economy concurrent with increasingly efficient solar systems has created market for larger Solar Energy System applications to power pumps, mini/micro grids for SMEs, internet kiosks etc. The rural farmers suffer from power shortage during the irrigation season and replacement of electric power pumps by solar pumps would save the grid system of $800 \mathrm{MW}$ load on the national grid. There is also increasing demand in rural health and education sector for Integrated Energy Systems to power lights, computers, TVs and refrigerators etc. Solar power can fill the niche. Solar power can also be used for early warning systems, emergency lighting, water desalination etc. in disaster zones. Increasing load shading in the urban areas has made solar power an attractive option for urban dwellers. 1 to $10 \mathrm{KW}$ systems to power lights, TVs and other appliances in domestic and commercial sector can easily create a niche, alongside diesel generators and Instant Power Supply etc.

- Bangladesh currently has a thriving RET sector with multiple companies manufacturing batteries, lightings and other solar accessories. Many of these companies are also exporting their products. Recently government has decided to include solar as a thrust sector in its industry policy.

\section{Policy Options: Building a Cutting Edge Entrepreneur Based Structure}

Bangladesh is uniquely positioned to reach 75 million people with renewable energy technologies by 2015 . However, we cannot tap into this huge potential through the existing model. We need to develop a cutting edge, efficient, flexible structure of rural based entrepreneurs who will take solar and other RET to every nook and corner of country to create a truly Solar Bangladesh. We need to focus on the following for the above transformation:

Creating Clean Energy Entrepreneurs 
- Our financial incentives are focused on microfinance institutions. Instead of this, we should help create business companies - small and big at the district/sub-district level linked with local entrepreneurs to widespread RET. This would create ownership, innovations and competition.

- We can create village based women entrepreneurs to promote Improved Cooking Stoves etc. They would also assemble, repair solar accessories and provide after sales service. They can be linked with small credit from rural financial institutions.

- We can create village based SME entrepreneurs to popularize solar pumps, mini -grids and biogas plants etc. The entrepreneurs would invest in the technology and earn a return by renting the technology to others. They can source loans from rural banks. . District/sub district level companies can help rural based entrepreneurs' source loans and the technology through guarantee, information, while national level companies would help district/sub-district level small and big companies to source finance, technology and build up their market.

\section{Focusing on an Efficient, Cost effective Supply Chain:}

- We need to set up more battery and other solar accessory manufacturing units to create a competitive environment, reduce costs and increase efficiency. Our government should try to attract foreign investment and R \& D in this sector.

- Currently solar practitioners are suffering from high battery price. This can be solved through more battery companies.

- We should concentrate on manufacturing export quality products to achieve economies of scale and tap into the world market. We can consider setting up Green Enterprise Zones especially for solar accessories such as charge controllers, invertors, mobile chargers etc with a focus on the rural areas to create green jobs.

- Biogas production can also be installed in combination with sanitation. Public toilets incorporating biogas units are particularly suitable for pen-urban areas and small towns in India where the supply of cooking gas is inadequate and wastewater treatment is unaffordable for the local authorities. Biogas systems can become part of decentralized wastewater treatment, and provide the fuel needed for heating water, for bathing and running generators to provide lighting in these facilities.

Easy Access to Green Credit \& Funds:
- Providing long term soft loans at 5 to $6 \%$ interest rate to all RET related businesses is needed. Present practice is that service providers can access soft loans after installing the systems. This does not take into account high upfront cost of sourcing supplies or developing the organizations. Similarly solar related manufacturing/ supply companies have to access loans at very high cost.

- Bangladesh Bank's refinancing scheme for RET is a step in the right direction. However most clients / renewable energy companies have been unable to access the loan because loan is to be provided to SHS customers and reimbursement is only after the installation. Energy Companies are not able to directly access this fund. This financing scheme has failed to gain momentum because of complex regulations and risk adverse tendency of commercial banks.

- Including a component in housing loans for installing solar.

- Creating a special green fund for providing grant for pilot testing new projects.

- Providing matching grants through local government institutions to green our infrastructure such as rural schools, clinics, cyclone shelters, etc.

- Creating a window in agricultural and other rural financial institutions to provide credit for RET, we can include training and credit for renewable energy technologies in our youth development programs. We should especially focus on SME loans and micro-credit loans for creating small and big entrepreneurs in the rural areas.

- Circulating green bonds for raising capital for solar and other RET.

\section{Passing Pro -renewable energy Laws}

- Providing special incentives such as long term soft loans, tax cuts for promoting solar both at the individual and commercial level.

- Removing all VAT/Tax for all type of solar accessories and raw materials to reduce cost. Bangladesh has one of the highest tariff structures in the world.

- Providing tax holidays and other benefits for investing in solar businesses.

- Making it mandatory to have all market places, restaurants, commercial buildings to install solar. At the same time government should provide soft loans for solar installation which would be part of housing loans.

Investing in Capacity Development and $R \& D$ 
- Developing a sustainable framework for developing human resources through country wide vocational centers, training institutes etc. Focus should be also on developing export quality human resource. This would also an incentive for private companies to participate with the maturing of the sector.

- Focusing on R \& D to adapt and develop innovative technologies. We should have innovation lab in all major universities which should be linked with international institutions and research institutions. Government should create an incentive structure such as competitions, awards to promote R \& D.

- Facilitating new ideas such as installment collection through mobile phones, prepaid cards to scale up and reduce transaction costs.

\section{Conclusion}

Bangladesh has given birth to one of most successful models to replicate RET. Keys to these successes are an innovative credit system, appropriate product design, grassroots based effective and efficient after sales service plus other consumer friendly options. However, the main factor behind the Bangladesh success story is that it empowers rural communities to own and uses RET and eventually become partners to bring and expand RET in their communities. It seeks solutions that empower women, the disadvantaged, create jobs, facilitate rural development and especially protect the environment.

To summarize, Bangladesh already has experience with RET projects. The potential of these project initiatives is high. Viable approaches need to be amplified to a broader context under a national RET strategy. In particular, the pilot schemes of RET development in Bangladesh need be scaled up to take a greater share in nation's energy mix. Mobilization of finance, realization of niche markets for RET and strengthening relevant institutions to implement RET policy direction are possible avenues to assist with this.

\section{References}

1. M S Islam and M R Islam (July 2011), Reducing biomass usage in rural areas of Bangladesh, South Asia Energy Network, Practical Action, Colombo, p. $4-5$

2. United States Agency for International Development (2011), Obtained from http://www.usaid.gov/bd/programs/energy.html [Accessed on 2nd October 2011]

3. Infrastructure Development Company Limited (2011), Obtained from http:// www.idcol.org/prishsm2004.php

[Accessed on 3rd October 2011] 